University of Nebraska - Lincoln

DigitalCommons@University of Nebraska - Lincoln

USDA National Wildlife Research Center - Staff Publications
U.S. Department of Agriculture: Animal and Plant Health Inspection Service

April 2007

\title{
Use of Implanted Radiotransmitters to Estimate Survival of Greater Sage-Grouse Chicks
}

\author{
Michael A. Gregg \\ United States Fish and Wildlife Service, Sheldon-Hart Mountain National Wildlife Refuge Complex \\ Mike R. Dunbar \\ United States Fish and Wildlife Service, Sheldon-Hart Mountain National Wildlife Refuge Complex \\ John A. Crawford \\ Oregon State University, Corvallis, OR
}

Follow this and additional works at: https://digitalcommons.unl.edu/icwdm_usdanwrc

Part of the Environmental Sciences Commons

\footnotetext{
Gregg, Michael A.; Dunbar, Mike R.; and Crawford, John A., "Use of Implanted Radiotransmitters to Estimate Survival of Greater Sage-Grouse Chicks" (2007). USDA National Wildlife Research Center - Staff Publications. 627.

https://digitalcommons.unl.edu/icwdm_usdanwrc/627
}

This Article is brought to you for free and open access by the U.S. Department of Agriculture: Animal and Plant Health Inspection Service at DigitalCommons@University of Nebraska - Lincoln. It has been accepted for inclusion in USDA National Wildlife Research Center - Staff Publications by an authorized administrator of DigitalCommons@University of Nebraska - Lincoln. 


\title{
Use of Implanted Radiotransmitters to Estimate Survival of Greater Sage-Grouse Chicks
}

\author{
MICHAEL A. GREGG,, ${ }^{1,2}$ United States Fish and Wildlife Service, Sheldon-Hart Mountain National Wildlife Refuge Complex, P.O. Box 111, \\ Lakeview, OR 97630, USA \\ MIKE R. DUNBAR, ${ }^{3}$ United States Fish and Wildlife Service, Sheldon-Hart Mountain National Wildlife Refuge Complex, P.O. Box 111, Lakeview, OR \\ 97630, USA \\ JOHN A. CRAWFORD, ${ }^{4}$ Department of Fisheries and Wildlife, Oregon State University, Corvallis, OR, 97331, USA
}

\begin{abstract}
Reduced chick survival has been implicated in declines of greater sage-grouse (Centrocercus urophasianus) populations. Because monitoring survival of unmarked sage-grouse chicks is difficult, radiotelemetry may be an effective technique to estimate survival rates, identify causes of mortality, and collect ecological data. Previous studies have used subcutaneous implants to attach radiotransmitters to hatchlings of several species of birds with precocial young. Previous researchers who used subcutaneous implants in free-ranging populations removed chicks from the capture location and implanted transmitters at an alternate site. Because logistics precluded removing newly hatched greater sagegrouse chicks from the field, we evaluated a method for implanting transmitters at capture locations. We captured 288 chicks from 52 broods and monitored 286 radiomarked chicks daily for 28 days following capture during May and June 2001-2002. Two (<1\%) chicks died during surgery and we did not radiomark them. At the end of the monitoring period, 26 chicks were alive and 212 were dead. Most (98\%, 207/212) radiomarked chick mortality occurred $\leq 21$ days posthatch and predation $(82 \%, 174 / 212)$ was the primary cause of death. Necropsies of 22 radiomarked chicks did not indicate inflammation or infection from implants, and they were not implicated in the death of any chicks. Fate of 48 chicks was unknown because of transmitter loss $(n=16)$, radio failure $(n=29)$, and brood mixing $(n=3)$. Overall, the 28 -day chick survival rate was $0.220(\mathrm{SE}=0.028)$. We found that mortalities related to the implant procedure and transmitter loss were similar to rates reported by previous researchers who removed chicks from capture sites and implanted transmitters at an alternate location. Subcutaneous implants may be a useful method for attaching transmitters to newly hatched sage-grouse chicks to estimate survival rates, identify causes of mortality, and collect ecological data. (JOURNAL OF WILDLIFE MANAGEMENT 71(2):646-651; 2007)
\end{abstract}

DOI: $10.2193 / 2006-353$

KEY WORDS Centrocercus urophasianus, chick, hatchling, mortality, radiotransmitter, sage-grouse, subcutaneous implant, survival, telemetry.

Limited information is available concerning survival and mortality factors of greater sage-grouse (Centrocercus urophasianus) chicks. Because poor chick survival may be related to sage-grouse population declines (Crawford and Lutz 1985, Connelly and Braun 1997), information on factors that influence survival is critical for management. This information has been difficult to obtain because most sage-grouse chick mortality typically occurs within 6 weeks after hatching (Drut 1992), when monitoring survival of unmarked chicks is difficult. Previous researchers identified habitat characteristics that may be important for sage-grouse chick survival by monitoring radiomarked females with broods (Wallestad 1971, Drut et al. 1994, Sveum et al. 1998), but they were unable to provide direct linkages between habitat parameters and chick survival rates. Research that establishes these linkages will be necessary before managers can develop specific management guidelines for sage-grouse brood-rearing habitat.

The development of miniaturized radiotransmitters affords the use of telemetry to estimate survival rates, identify

1 E-mail: mike_gregg@fws.gov

${ }^{2}$ Present address: United States Fish and Wildlife Service, Hanford Reach National Monument, 3250 Port of Benton Boulevard, Richland, WA 99354 USA.

${ }^{3}$ Present address: United States Department of Agriculture, National Wildlife Research Center, 4101 LaPorte Avenue, Fort Collins, CO 80521 USA.

${ }^{4}$ Present address: P.O. Box 6622, Bend, OR 97701 USA. causes of mortality, and collect ecological data for hatchlings of precocial species. Attachment techniques for miniature transmitters include backpacks (Speake et al. 1985), prong and suture (Mauser and Jarvis 1991, Davis et al. 1999), glue (Bowman et al. 2002, Spears et al. 2002), suture (Larson et al. 2001, Burkepile et al. 2002), and subcutaneous implants (Ewing et al. 1994, Korschgen et al. 1996b). The subcutaneous implant technique was one of the first methods developed to mark hatchlings of precocial birds (Korschgen et al. 1996b) and originally was designed for use in waterfowl (Krementz and Pendleton 1991, Korschgen et al. 1996a). More recently, subcutaneous implants have been used to radiomark hatchlings of gallinaceous species including ring-necked pheasants (Phasianus colchicus, Riley et al. 1998), wild turkeys (Meleagris gallopavo, Hubbard et al. 1999), and ruffed grouse (Bonasa umbellus, Larson et al. 2001).

Burkepile et al. (2002) evaluated a suture method to externally attach transmitters to greater sage-grouse chicks, but researchers have not examined any other method of radio attachment for sage-grouse hatchlings. We evaluated subcutaneous implants for attaching transmitters to newly hatched sage-grouse chicks. Previous researchers who used subcutaneous implants in free-ranging populations of gallinaceous species relocated chicks to alternate sites (e.g., vehicle, research facility) to implant transmitters and returned radiomarked chicks to the brood after surgery (Riley et al. 1998, Hubbard et al. 1999, Larson et al. 2001). 
Because logistics precluded removal of sage-grouse chicks from the field to implant transmitters, our objectives were to develop field methods for implanting transmitters and document effects of the procedure on survival. We also identified causes of death and estimated survival of radiomarked chicks to 28 days following capture.

\section{STUDY AREA}

We conducted our study at 3 areas during 2001 and 2002 in the northern Great Basin of southeastern Oregon and northwestern Nevada, USA. The Beatys Butte allotment, located in Oregon, was administered by the Bureau of Land Management and encompassed 220,301 ha. Hart Mountain National Antelope Refuge, located in Oregon, and Sheldon National Wildlife Refuge, located in Nevada, were administered by the United States Fish and Wildlife Service and encompassed 114,375 ha and 232,294 ha, respectively. Our study areas were characteristic of shrub-steppe habitat and consisted of flat sagebrush (Artemisia spp.) plains interrupted by mountains, tablelands, ridges, and draws. Elevation ranged from $1,200 \mathrm{~m}$ to $2,450 \mathrm{~m}$. Annual mean precipitation and minimum and maximum temperatures ranged from $29 \mathrm{~cm}$ to $33 \mathrm{~cm}$ and $-1.5^{\circ} \mathrm{C}$ to $14.3^{\circ} \mathrm{C}$, respectively (Western Regional Climate Center 2005).

Primary plant communities used by sage-grouse broods included low sagebrush (Artemisia arbuscula), Wyoming big sagebrush (Artemisia tridentata wyomingensis), mountain big sagebrush (Artemisia tridentata vaseyana), and Antelope bitter-brush (Purshia tridentata). Mammalian and avian predators of chicks (Schroeder and Baydack 2001) common to the study areas included coyotes (Canus latrans), bobcats (Felis rufus), weasels (Mustela spp.), red-tailed hawks (Buteo jamaicensis), rough-legged hawks (Buteo lagopus), northern harriers (Circus cyaneus), golden eagles (Aquila chrysaetos), and common ravens (Corvus corax). Less common, but possible important predators of sage-grouse chicks included Swainson's hawks (Buteo swainsoni) and ferruginous hawks (Buteo regalis). Potential reptilian predators of chicks included western rattlesnakes (Crotalus viridis) and gopher snakes (Pituophis catenifer).

\section{METHODS}

We captured and fitted female sage-grouse with 20-g necklace-mounted radiotransmitters (Advanced Telemetry Systems, Isanti, MN) during March and April 2001 and 2002 (Gregg et al. 2006). We used protocols described by Gregg et al. (2006) to locate nest sites and monitor nesting females. We estimated the nest initiation date for each female from telemetry data and predicted the hatch date based on an incubation period of 26 days (Schroeder 1997). We monitored nesting females daily near predicted hatch dates and when monitoring indicated that incubation had ceased, we inspected nest sites to determine nest fate and classified nests as successful if $\geq 1 \mathrm{egg}$ hatched.

We flushed radiomarked females with broods and captured as many chicks by hand as we could visually locate. We postponed capture during periods of precipita- tion or freezing temperatures to reduce potential for hypothermia, but we typically captured chicks $24-36$ hours after hatching. We captured chicks at all times of day during 2001, but to reduce capture time and minimize brood disturbance we attempted most captures just after sunrise during 2002. We weighed chicks to the nearest $0.1 \mathrm{~g}$ and subcutaneously implanted transmitters anterior of the scapulars. We used 2 different-sized implantable transmitters (model BD2-A, Holohil Systems Ltd., Carp, ON, Canada) with a normal battery life of 28 days (range 21-35). The large transmitter was $17 \times 8 \times 5 \mathrm{~mm}$ and weighed 1.1 g. The small transmitter was $14 \times 6 \times 4 \mathrm{~mm}$ and the weight was reduced to $0.85 \mathrm{~g}$ by decreasing battery size and the transmitter's plastic coating. All transmitters had $23-\mathrm{cm}$ stranded steel wire antennas with black nylon coating.

We conducted surgeries at capture locations (Fig. 1). We moistened the implant area and disinfected surgical tools and transmitters with chlorhexidine diacetate (Nolvasan solution, Wyeth, Madison, NJ) before the procedure, but we did not anesthetize chicks (American Ornithologists' Union 1988). We lifted the skin with forceps below the nape of the neck and made a 5-mm incision perpendicular with the vertebrae with $11.4-\mathrm{cm}$ surgical scissors. We inserted the scissors into the incision and slowly opened them to create a pocket approximately $25 \mathrm{~mm}$ deep. We threaded the transmitter antenna through a 22-gauge hypodermic needle (Monoject, The Kendall Co., Mainsfield, MA) with the hub removed. We lifted the skin above the pocket with forceps and inserted the needle into the incision until it exited at the posterior end of the pocket. We removed the needle and antenna through the posterior hole and placed the transmitter under the skin posterior to the incision by lifting the skin at the incision and gently pulling on the antenna. We closed the incision parallel to the midline with a single suture of polyglycolic absorbable material (4-0 Dexon II, United States Surgical, Norwalk, CT) and one drop of surgical glue (Nexaband S/C, Closure Medical Corp, Raleigh, NC). The Oregon State University Laboratory Animal Resource Center (Animal Care and Use Protocol no. 2656) approved this procedure. We released chicks from a brood together after we implanted all transmitters.

We monitored radiomarked chicks daily for 28 days following capture to estimate survival and determine causes of mortality. We assumed that radiomarked chicks found within a 30-m radius around the female were alive. We did not intentionally flush females and broods to avoid disturbance. We used ground and aerial telemetry to locate radiomarked chicks separated from brood females. We recovered chick remains and transmitters and classified chick deaths into predation, exposure, and unknown based on necropsy results and evidence found at recovery sites. Dead intact chicks were necropsied by a local veterinarian or staff at the Washington Animal Disease Diagnostic Laboratory, Washington State University, Pullman. We identified predation as cause of death when we found transmitters with bite marks or in scat or when recovered chick remains indicated predation. We also assigned predation as cause of 

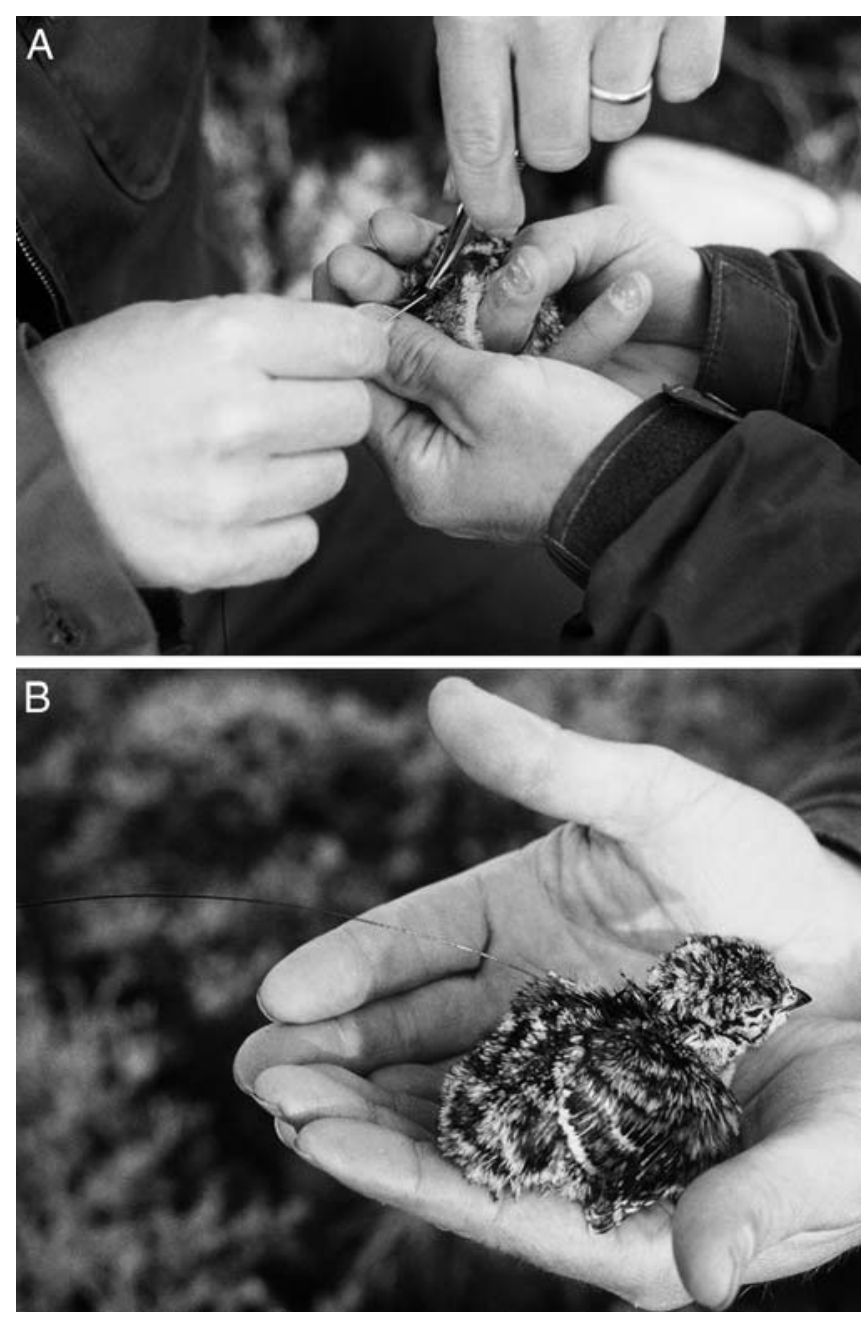

Figure 1. We implanted transmitters in greater sage-grouse chicks at capture locations at 3 study areas in Oregon and Nevada, USA, 2001-2002. (A) One individual held the chick and a second person trained in the method implanted the transmitter. (B) A 1-day-old greater sage-grouse chick after completion of the implant procedure (photos by K. Goldie).

death when radiomarked chicks disappeared with no evidence of radio failure and we assumed that a predator destroyed the chick and transmitter. We classified deaths as exposure when we found intact dead chicks near capture sites $<1$ day after marking, after brood females were depredated, or in conjunction with freezing temperatures and precipitation. We classified cause of death as unknown when we recovered intact chicks, excluded other mortality factors, and necropsy results did not provide a definitive diagnosis.

We estimated survival probabilities of radiomarked chicks with the Kaplan-Meier product limit estimator (Kaplan and Meier 1958). We defined the day of marking as time $=0$ for all chicks, regardless of capture date. We used log-rank tests to identify differences in survival functions between chicks with small and large transmitters (Allison 1995, Larson et al. 2001). We right-censored radiomarked chicks with unknown fate on the last date known alive. We radiomarked multiple chicks from a single brood and may have violated the assumption of independent observations for the Kaplan-
Meier survival probabilities. Our estimates of survival were unbiased, but we may have underestimated standard errors (Pollock et al. 1989, Flint et al. 1995). Therefore, we used a bootstrap resampling method (Efron and Tibshirani 1993, Flint et al. 1995) with 500 replicates to estimate standard errors from the Kaplan-Meier procedure for each survival estimate. We used SAS statistical software (PROC LIFETEST, Version 8.2; SAS Institute, Cary, NC) for all survival analyses. We applied an alpha of 0.05 for all tests.

\section{RESULTS}

We captured 288 chicks from 52 broods between 18 May and 12 June 2001 and 10 May and 16 June 2002 (Table 1). The number of captured chicks per brood ranged from 1 to 9. Mean weight of chicks was $29.5 \mathrm{~g}(\mathrm{SE}=0.2)$ and transmitters averaged $3.6 \%(\mathrm{SE}=0.03)$ of chick body weights. Two $(<1 \%)$ chicks died during surgery and we did not radiomark them. We implanted large transmitters in 228 chicks. We only used small transmitters during 2002 and implanted them in 58 chicks. Mean age of chicks at capture with large $(1.3 \pm 0.1 \mathrm{~d})$ and small $(1.4 \pm 0.1 \mathrm{~d})$ implanted transmitters was similar. We typically completed the surgical procedure in 3-5 minutes per chick. We reduced the time required to complete the entire procedure (capture and marking) by approximately $50 \%(\leq 90 \mathrm{~min} /$ brood and $\leq 45 \mathrm{~min} /$ brood during 2001 and 2002, respectively) by restricting the capture period to early morning. No females abandoned broods because of our activities and they often remained nearby while we handled chicks. Six radiomarked chicks from 5 broods were adopted by unmarked females 5 to 22 days following capture.

Nearly all chick deaths $(98 \%, 207 / 212)$ occurred $\leq 21$ days posthatch. Predation was the primary cause of death during both years and accounted for $82 \%(174 / 212)$ of all mortality. We attributed chick predation to mammalian $(n=$ $88)$, avian $(n=20)$, and reptilian $(n=4)$ predators. Predator identification was not possible for $36 \%(62 / 174)$ of depredated chicks because of insufficient evidence. Exposure was the second leading cause of mortality for radiomarked chicks and accounted for $12 \%(25 / 212)$ of chick deaths. We associated death of 11 chicks with cold, wet weather shortly after capture; we found one chick dead 6 days after capture with the transmitter antenna tangled in a shrub, one chick drowned, and one chick died after the brood female was depredated. The remaining 11 chicks died $<1$ day after capture and we found them dead at or near capture sites. Cause of death was unknown for $6 \%$ (13/212) of our radiomarked chicks, which we recovered 2-15 days posthatch. Necropsy results from one of these chicks revealed that we may have inadvertently entered the dorsal thoracic cavity during surgery, which may have resulted in pulmonary hemorrhage that could have caused death. However, necropsy results were not definitive and this chick survived to 15 days posthatch and had excellent muscling, a full crop, and ventricular and intestinal contents at time of death. Necropsies of an additional 21 chicks failed to provide a 
Table 1. Number of greater sage-grouse broods and chicks captured at 3 study areas in Oregon and Nevada, USA, 2001-2002.

\begin{tabular}{|c|c|c|c|c|c|c|}
\hline \multirow[b]{3}{*}{ Yr } & \multicolumn{6}{|c|}{ Study areas } \\
\hline & \multicolumn{2}{|c|}{ Hart Mountain } & \multicolumn{2}{|c|}{ Beatys Butte } & \multicolumn{2}{|c|}{ Sheldon } \\
\hline & Broods & Chicks & Broods & Chicks & Broods & Chicks \\
\hline 2001 & 10 & 51 & 7 & 37 & 6 & 33 \\
\hline 2002 & 9 & 53 & 12 & 64 & 8 & 50 \\
\hline Total & 19 & 104 & 19 & 101 & 14 & 83 \\
\hline
\end{tabular}

definitive diagnosis, but we detected no inflammation or infection from implants.

Overall, the 28-day survival rate for 2001-2002 was 0.220 $(\mathrm{SE}=0.028)$. At the end of the monitoring period, 26 chicks were alive and 212 were dead. We censored 48 chicks because we were unable to determine fate. Brood mixing resulted in loss of radio contact of 3 chicks and monitoring data indicated that 29 transmitters failed and 16 large transmitters possibly fell off. We identified radio failure by changes in signal characteristics or irregular performance immediately preceding disappearance of chicks, and we found transmitters that had apparently been dropped undamaged in the vicinity of radiomarked broods with no additional evidence present to confirm death. Dried skin was attached to most of these transmitters, which also indicated that they could have sloughed off surviving chicks. If we treated these 16 chicks as dead, the 28-day survival rate was reduced to $0.171(\mathrm{SE}=0.024)$. We found no evidence that small transmitters were lost. Survival did not differ between study areas for small or large transmitters during 2002 (logrank test, $\left.\chi_{1}^{2} \leq 3.538, P \geq 0.170\right)$. Therefore, we pooled data from all areas to test for effects of transmitter size on survival. We found no difference in 28-day survival rates between chicks with large and small transmitters, regardless if chicks with sloughed transmitters were censored or treated as dead (log-rank test, $\chi_{1}^{2} \leq 0.154, P \geq 0.694$; Fig. 2). Most radio failure $(90 \%, 26 / 29)$ and transmitter loss $(87 \%$, 14/16) occurred $\geq 12$ days after capture.

\section{DISCUSSION}

Although death of chicks directly related to implant surgeries was low during our study $(<1 \%)$, other researchers who used the technique and implanted transmitters at an alternate location reported no mortality during the surgical procedure (Korschgen et al. 1996b, Hubbard et al. 1999, Larson et al. 2001). Death of one chick likely was related to the experience of the individual conducting the surgery and the other chick apparently died from stress associated with capture and surgery. We found that implanting transmitters in the field did not result in inflammation or infection of the implant site and apparently was not a contributing factor to chick mortality during our study. Ewing et al. (1994) reported no signs of infection in captive ring-necked pheasant chicks with implanted transmitters. Similarly, Korschgen et al. (1996b) reported that subcutaneous implants in canvasback (Aythya valisineria) ducklings caused

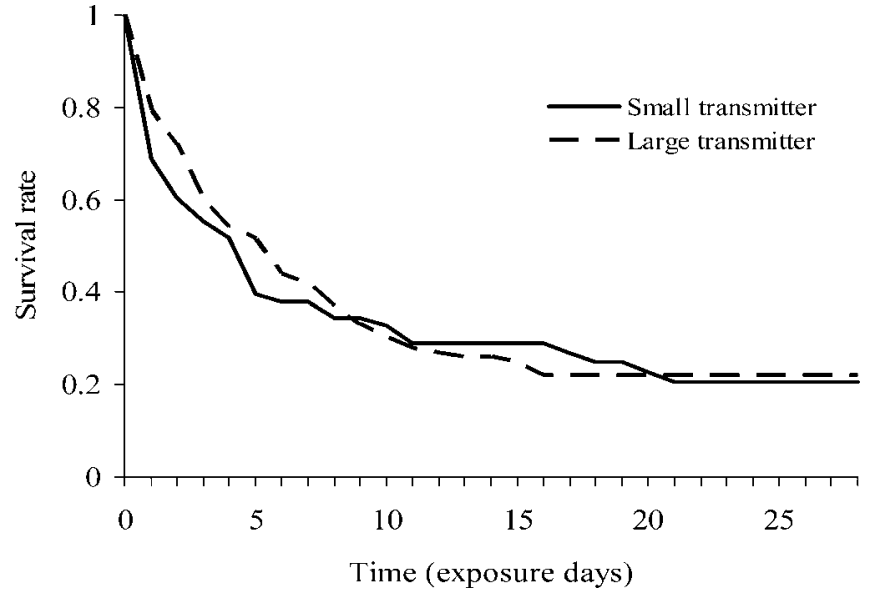

Figure 2. Comparison of survival rates to 28 days following capture for greater sage-grouse chicks with small (0.85 g, $n=58)$ and large (1.1 g, $n=$ 107) subcutaneously implanted transmitters, Oregon and Nevada, USA, 2002.

only minor inflammation that did not contribute to any duckling deaths.

Subcutaneous implanted transmitters may have indirectly influenced chick survival to some extent. We recovered 11 $(4 \%)$ dead chicks $<1$ day after marking near capture locations; these chicks apparently died from exposure. Similarly, Hubbard et al. (1999) reported that $9(8 \%)$ wild turkey poults with implanted transmitters failed to leave the point of release and died from exposure. Bowman et al. (2002) indicated that subcutaneously implanted transmitters in captive turkey poults had a short-term (2-4-hr) negative effect on mobility. Impaired mobility could increase the risk of exposure and other mortality factors because newly marked chicks may lose contact with their brood female. We departed capture sites immediately after releasing radiomarked sage-grouse chicks and did not evaluate mobility, but we noted that a few radiomarked chicks were unstable and had difficulty walking immediately after release. Mauser and Jarvis (1991) reported that lack of mobility was related to transmitter size for captive mallard (Anas platyrhynchos) ducklings with externally attached radios. Of the 11 sagegrouse chicks we recovered at capture sites, 10 had large transmitters. However, we also documented several cases of entire and partial brood loss within 24 hours after hatching for unmarked broods during both years of our study and we observed similar proportions of radiomarked and unmarked chicks during flush counts at 28 days posthatch (M. Gregg, United States Fish and Wildlife Service, unpublished data). Hence, the indirect effect of implants on sage-grouse chick survival during our study was difficult to ascertain, but appeared to be low.

Our survival estimate for sage-grouse chicks with implanted transmitters $(\hat{S}=0.220)$ was low compared to survival reported for sage-grouse chicks with external transmitters $(\hat{S}=0.432)$ in Alberta, Canada (Aldridge 2005). Survival differences between studies could have been related to radio attachment technique, but a direct comparison of survival between implanted and externally radioed sage-grouse chicks is not available. Larson et al. 
(2001) reported that survival of ruffed grouse chicks was lower for individuals with implanted transmitters compared to individuals with radios sutured to their back. However, they indicated that the difference in survival most likely was related to loss of implanted transmitters, but they did not rule out greater mortality of chicks with implants. Results from Larson et al. (2001) were not directly comparable with our study because they monitored marked chicks from near hatching to autumn dispersal and compared survival between the 2 techniques at approximately 85 days postmarking. Survival rates apparently were similar for chicks with implanted and sutured transmitters 28 days after chicks were marked (Larson 1998, Larson et al. 2001). In addition, Kenow et al. (2003) suggested that the response of chicks to comparable transmitters and attachment techniques might be species-specific.

We found no difference in survival probabilities between small and large transmitters, which was consistent with results reported by Burkepile et al. (2002) for radiomarked sage-grouse chicks in Idaho. However, our results suggested that transmitter size was related to retention rates. During our study, we did not know the fate of 16 chicks marked with large transmitters because we recovered radios without evidence of death. Large transmitters tended to fit tightly under the skin and we speculated that necrosis of the tissue on top of the radio resulted in scabs that were lost with transmitters, which was supported by radios recovered undamaged with dead skin attached. Extrusion of implanted transmitters caused by necrosis of the skin above the implant has been reported for captive turkey poults (Bowman et al. 2002) and ring-necked pheasant chicks (Ewing et al. 1994), but the necrosis apparently did not influence survival. Small transmitters were loose under the skin, which likely reduced necrosis of skin over the radio. In addition, small transmitters were easier to implant and required less time to implant than large transmitters. Kenow et al. (2003) also reported greater retention rates for small $(0.76 \mathrm{~g})$ compared to large $(1.5 \mathrm{~g})$ implanted transmitters in common loon (Gavia immer) chicks. Overall, loss of implanted transmitters during our study was comparable to loss of transmitters implanted in captive ring-necked pheasant chicks (Ewing et al. 1994) and transmitters sutured on free-ranging sage-grouse chicks (Burkepile et al. 2002).

Larson et al. (2001) reported a preference for the suture method for attaching transmitters to ruffed grouse chicks because external suturing required less time, equipment, and expertise compared to the implant technique. In addition, wetting of chicks was not required and there was less chance for trauma (Larson et al. 2001). The suture method has been used to attach transmitters to sage-grouse chicks in Alberta, Canada (Aldridge 2005), Colorado, USA (T. Thompson, University of Idaho, personal communication), and Idaho, USA (Burkepile et al. 2002), apparently with good success. Sutured transmitters on sage-grouse chicks were easily replaced (Burkepile et al. 2002; T. Thompson, University of Idaho, personal communication), but the use of subcutaneous implants does not preclude radio replacement for long-term monitoring of chicks (Korschgen et al. 1996a, Kenow et al. 2003). Bowman et al. (2002) recommended glued transmitters over implants for estimating short-term survival ( $<29$ d) of wild turkey poults. Glued transmitters were preferred because the simple application procedure required little training and poults with glued transmitters did not exhibit any impaired mobility that could potentially compromise survival (Bowman et al. 2002). However, researchers have not evaluated glued transmitters for sagegrouse chicks.

Implanted transmitters in sage-grouse may not provide significant advantages compared with externally attached radios to warrant the greater training and expertise required to properly apply the technique. However, Krementz and Pendleton (1991) reported that implanted transmitters provided more accurate information on duckling mortality factors than did external transmitters. Because we only used implanted transmitters during our study, we were unable to make this comparison for sage-grouse. A direct comparison between implanted and external methods would be useful to determine the most appropriate technique to radiomark sage-grouse chicks. We also recommend research that compares survival of marked and unmarked sage-grouse chicks in free-ranging populations to identify potential bias in survival estimates from telemetry techniques. Previous researchers have reported similar survival rates for marked compared to unmarked chicks of other bird species with precocial young (Korschgen et al. 1996b, Hubbard 1997, Kenow et al. 2003). However, researchers have not conducted studies to compare survival of marked and unmarked free-ranging sage-grouse chicks, and the effects of transmitters on survival are unknown.

\section{MANAGEMENT IMPLICATIONS}

Subcutaneous implants may be a useful technique for attaching transmitters to sage-grouse chicks. Our results indicated that implanting transmitters in the field did not result in greater mortality compared to other researchers who have used the technique. However, the implant technique requires training and practice. Training should be provided by individuals proficient with the surgical procedure necessary to implant transmitters. We recommend that individuals practice on dead chicks or domestic chicken chicks to become skilled with the surgical procedures before using the technique. We found that once individuals mastered the surgical procedures, they could easily implant transmitters in $<5$ minutes. We recommend using the smallest available transmitter that meets study objectives with the implant technique. Our results revealed that smaller transmitters would increase retention rates and reduce chick-handling time. Small transmitters were easier to implant, less intrusive, and may reduce any potential bias in survival estimates.

\section{ACKNOWLEDGMENTS}

The United States Fish and Wildlife Service, Bureau of Land Management, National Fish and Wildlife Foundation, 
Oregon Department of Fish and Wildlife, Nevada Division of Wildlife, Nevada Bighorns Unlimited, and Nevada Chukar Foundation funded our research. We acknowledge logistic and technical support provided by J. T. Forbes and V. M. Stofleth of the Bureau of Land Management and J. Lane of the Beatys Butte Grazing Association. We thank J. Crossingham, M. Cunningham, D. M. Davis, J. Zoller, D. Moen, S. Selser, M. Sheperdson, J. Stiver, S. Torland, M. A. Westbrock, and N. M. Woodard for assistance with conducting this research. J. K. Barnett, C. A. Hagen, and M. D. Pope provided comments on an earlier version of this manuscript.

\section{LITERATURE CITED}

Aldridge, C. L. 2005. Identifying habitats for persistence of greater sagegrouse (Centrocercus urophasianus) in Alberta, Canada. Dissertation, University of Alberta, Edmonton, Canada.

Allison, P. D. 1995. Survival analysis using the SAS system: a practical guide. SAS Institute, Inc., Cary, North Carolina, USA.

American Ornithologists' Union. 1988. Report of committee on the use of wild birds in research. Auk 105(1, supplement):1A-41A.

Bowman, J., M. C. Wallace, W. B. Ballard, J. H. Brunjes, IV, M. M. Miller, and J. M. Hellman. 2002. Evaluation of two techniques for attaching radio transmitters to turkey poults. Journal of Field Ornithology 73:276-280.

Burkepile, N. A., J. W. Connelly, D. W. Stanley, and K. P. Reese. 2002. Attachment of radiotransmitters to one-day-old sage grouse chicks. Wildlife Society Bulletin 30:93-96.

Connelly, J. W., and C. E. Braun. 1997. Long-term changes in sage grouse Centrocercus urophasianus populations in western North America. Wildlife Biology 3:229-234.

Crawford, J. A., and R. S. Lutz. 1985. Sage grouse population trends in Oregon, 1941-1983. The Murrelet 66:69-74.

Davis, J. B., D. L. Miller, R. M. Kaminski, and M. P. Vrtiska. 1999. Evaluation of a radio transmitter for wood duck ducklings. Journal of Field Ornithology 70:107-113.

Drut, M. S. 1992. Habitat use and selection by sage grouse broods in southeastern Oregon. Thesis, Oregon State University, Corvallis, USA.

Drut, M. S., J. A. Crawford, and M. A. Gregg. 1994. Brood habitat use by sage grouse in Oregon. Great Basin Naturalist 54:170-176.

Efron, B., and R. J. Tibshirani. 1993. An introduction to the bootstrap. Chapman and Hall, New York, New York, USA.

Ewing, D. E., W. R. Clark, and P. A. Vohs. 1994. Evaluation of implanted radio transmitters in pheasant chicks. Journal of the Iowa Academy of Sciences 101:86-90.

Flint, P. L., K. H. Pollock, D. Thomas, and J. S. Sedinger. 1995. Estimating prefledging survival: allowing for brood mixing and dependence of brood mates. Journal of Wildlife Management 59:448-455.

Gregg, M. A., M. R. Dunbar, J. A. Crawford, and M. D. Pope. 2006. Total plasma protein and renesting by greater sage-grouse. Journal of Wildlife Management 70:472-478.

Hubbard, M. W. 1997. Wild turkey poult survival in south-central Iowa. Dissertation, Iowa State University, Ames, USA.

Hubbard, M. W., D. L. Garner, and E. E. Klaas. 1999. Wild turkey poult survival in southcentral Iowa. Journal of Wildlife Management 63:199203.

Kaplan, E. L., and P. Meier. 1958. Nonparametric estimation from incomplete observations. Journal of the American Statistical Association 53:457-481.

Kenow, K. P., M. W. Meyer, F. Fournier, W. H. Karasov, A. Elfessi, and S. Gutreuter. 2003. Effects of subcutaneous transmitter implants on behavior, growth, energetics, and survival of common loon chicks. Journal of Field Ornithology 74:179-186.

Korschgen, C. E., K. P. Kenow, W. L. Green, D. H. Johnson, M. D. Samuel, and L. Sileo. 1996a. Survival of radiomarked canvasback ducklings in northwestern Minnesota. Journal of Wildlife Management 60:120-132.

Korschgen, C. E., K. P. Kenow, W. L. Green, M. D. Samuel, and L. Sileo. 1996b. Technique for implanting radio transmitters subcutaneously in day-old ducklings. Journal of Field Ornithology 67:392-397.

Krementz, D. G., and G. W. Pendleton. 1991. Movements and survival of American black duck and mallard broods on Chesapeake Bay. Proceedings of the Annual Conference of Southeastern Association of Fish and Wildlife Agencies 45:156-166.

Larson, M. A. 1998. Nesting success and chick survival of ruffed grouse (Bonasa umbellus) in northern Michigan. Thesis, Michigan State University, East Lansing, USA.

Larson, M. A., M. E. Clark, and S. R. Winterstein. 2001. Survival of ruffed grouse chicks in northern Michigan. Journal of Wildlife Management 65: 880-886.

Mauser, D. M., and R. L. Jarvis. 1991. Attaching radio transmitters to 1day-old mallard ducklings. Journal of Wildlife Management 55:488-491.

Pollock, K. H., S. R. Winterstein, C. M. Bunck, and P. D. Curtis. 1989. Survival analysis in telemetry studies: the staggered entry design. Journal of Wildlife Management 53:7-15.

Riley, T. Z., W. R. Clark, D. E. Ewing, and P. A. Vohs. 1998. Survival of ring-necked pheasant chicks during brood rearing. Journal of Wildlife Management 62:36-44.

Schroeder, M. A. 1997. Unusually high reproductive effort by sage grouse in a fragmented habitat in north-central Washington. Condor 99:933941.

Schroeder, M. A., and R. K. Baydack. 2001. Predation and management of prairie grouse. Wildlife Society Bulletin 29:24-32.

Speake, D. W., R. Metzler, and J. McGlincy. 1985. Mortality of wild turkey poults in northern Alabama. Journal of Wildlife Management 49: 472-474.

Spears, B. L., W. B. Ballard, M. C. Wallace, R. S. Phillips, D. H. Holdstock, J. H. Brunjes, R. Applegate, P. S. Gipson, M. S. Miller, and T. Barnett. 2002. Retention times of miniature radiotransmitters glued to wild turkey poults. Wildlife Society Bulletin 30:861-867.

Sveum, C. M., J. A. Crawford, and W. D. Edge. 1998. Use and selection of brood-rearing habitat by sage grouse in south central Washington. Great Basin Naturalist 58:344-351.

Wallestad, R. O. 1971. Summer movements and habitat use by sage grouse broods in central Montana. Journal of Wildlife Management 35:129-136.

Western Regional Climate Center. 2005. Historical climate information. Western U.S. historical summaries (individual stations), Hart Mountain Refuge, Oregon; Sheldon, Nevada. <http://www.wrcc.dri.edu $>$ Accessed 23 Jun 2005.

Associate Editor: Chamberlain. 